\title{
Sstr2A immunohistochemical expression in human meningiomas: Is there a correlation with the histological grade, proliferation or microvessel density?
}

\author{
V. BARRESI ${ }^{1}$, C. ALAFACI ${ }^{2}$, F. SALPIETRO $^{2}$ and G. TUCCARI ${ }^{1}$ \\ Departments of ${ }^{1}$ Human Pathology and ${ }^{2}$ Neurosurgery, University of Messina, Italy \\ Received February 13, 2008; Accepted March 28, 2008
}

DOI: $10.3892 /$ or_00000032

\begin{abstract}
Somatostatin anti-proliferative and anti-angiogenic activities, together with the expression of somatostatin receptors (sstrs), account for the use of somatostatin analogues in the treatment of human tumours. In the present study, sstr $2 \mathrm{~A}$ immunohistochemical expression was analyzed in grade II and III meningiomas and was compared with that revealed in grade I meningiomas. Thirty-five formalin-fixed paraffinembedded meningiomas, comprising 13 grade I, 19 grade II and 3 grade III tumours, according to the WHO 2007 classification, were submitted to immunohistochemical assays for sstr2A. Moreover, in the same cohort of tumours, the immunoexpression of CD105, a specific marker for neoangiogenesis, as well as the Ki-67 labelling index (LI), reflecting the proliferative activity of the meningiomas, were recorded. Sstr2A immunoreaction was evidenced in $26 / 35$ cases and was localized at the cytoplasm and the plasma membrane in 12 and in 14 cases, respectively. Specifically, a positive staining was found in $7 / 13$ grade I, in 16/19 grade II and in $3 / 3$ grade III tumours, thus demonstrating that $s s t r 2 A$ is frequently expressed in high grade meningiomas. A significantly higher microvessel density (MVD), assessed by CD105 immunostaining and Ki-67 LI were evidenced in high grade meningiomas. A significant correlation was recorded between sstr $2 A$ expression and a high MVD of the meningiomas. The existence of a correlation between sstr $2 A$ expression and the entity of neo-angiogenesis provides the basis for the use of somatostatin analogue-based therapies in the treatment of meningiomas.
\end{abstract}

\section{Introduction}

Somatostatin is a 14- or 28-amino acid peptide hormone, which has been detected throughout the human body (1). It exerts an

Correspondence to: Dr Valeria Barresi, Department of Human Pathology, Policlinico Universitario G. Martino, Pad D, Via Consolare Valeria, 98125 Messina, Italy

E-mail: valeriabarresi@hotmail.com

Key words: somatostatin receptor $2 \mathrm{~A}$, meningioma, microvessel density, CD105, therapy, immunohistochemistry inhibitory function on a number of physiological processes, including pituitary hormone secretion (2) and the neurotransmission in the central nervous system (1). Antiproliferative and anti-angiogenic activities have been attributed to somatostatin in human tumours (3-5). Somatostatin action is mediated by six specific somatostatin receptors (sstrs), named sstrl, sstr $2 A$, sstr $2 B$, sstr3, sstr4 and sstr5, which belong to a family of seven transmembrane domain G-protein coupled receptors, which are encoded on five different chromosomes (6). Among these receptor subtypes, sstr $2 A$ and $s s t r 2 B$ are encoded on chromosome 17 and are generated through the alternative splicing of sstr 2 mRNA (7). The expression of sstrs has been demonstrated in a series of normal human tissues (8), including those of the adult and fetal central nervous system $(9,10)$, as well as in many human tumours (11-13). Therefore the use of somatostatin analogues in the treatment of human neoplasms gets a rationale in sstr expression in neoplastic tissues together with the somatostatin inhibitory effect on proliferation and angiogenesis.

Among the central nervous system tumours, sstr expression has been evidenced in gliomas, with $s s t r 2 A$ as the most commonly expressed sstr (14). Moreover, a high frequency of sstr $2 \mathrm{~A}$ expression has been reported in medulloblastomas, paragangliomas and in neuroblastomas, with a cytoplasmic and membranous localization of this receptor (15). When sstr expression was investigated through immunohistochemistry or RT-PCR in meningiomas $(14,16-18)$, a high density of these proteins or of their mRNA was found in these neoplasias, with $\operatorname{sstr} 2 A$ as the most frequently expressed sstr (18). It is well known that meningiomas are common central nervous system tumours, accounting for $\sim 25 \%$ of the intracranial neoplasms (19). According to the WHO criteria (19), they are histologically classified into three grades of malignancy. The grade I meningiomas are the most frequent and are considered as benign, slowly growing and easily surgically removable tumours; by contrast, grade II and III represent $\sim 20 \%$ of all meningiomas and are characterized by a worse clinical course (20) and a higher proliferation index (20) and microvessel density (MVD) $(21,22)$. Thus far, all the studies that have evaluated sstrs expression in surgically resected meningiomas have mostly included cases histologically classified as grade I. On the contrary, only a small number $(17,18)$, if not at all $(14,16)$, of grade II and III meningiomas have been examined in these 
studies. In view of this, in the present study we aimed to analyze the immunohistochemical expression of $\operatorname{sstr} 2 A$, the most frequent sstr in meningiomas, in a series of cases comprising of a higher number of grade II and III meningiomas in comparison to the other studies (14,16-18). In addition, we thought it would be of interest to investigate the correlation between sstr $2 \mathrm{~A}$ immunoexpression and the histological grade as well as the proliferation index and the MVD of the tumours of our cohort.

\section{Materials and methods}

Thirty-five surgically resected meningiomas, obtained from an equal number of patients ( 22 female and 13 male patients; age range 31-84 years; mean age 64 years), were collected from the files of the Department of Human Pathology of the University of Messina, Italy. Specifically, 19 (54\%) cases of meningiomas displaying a histological grade II and 3 characterized by a histological grade III (9\%) were selected among meningiomas which occurred between 2006 and 2007. Then, a comparable number of meningiomas with a histological grade I (13 cases; 37\%) were collected. All the cases were histologically classified according to the criteria proposed in the WHO 2007 classification of central nervous system tumours (19). The cohort comprised 3 anaplastic or grade III meningiomas, 16 atypical, 1 clear cell and 2 chordoid meningiomas among the grade II tumours and 7 meningothelial, 1 transitional, 2 fibrous, 1 secretory and 2 microcystic meningiomas as grade I cases. For each case, the clinicopathological data, including the patient's age and gender, as well as the site, the histological grade and the Simpson grade of surgical resection (23) of the tumours were available. The tumour localization was subdivided into three sites: convexity $(37 \%)$, parasagittal $(37 \%)$ and basal $(26 \%)$. On the basis of the Simpson grade, two main groups were considered: the first one $(60 \%)$ collecting grade 1 tumours (complete excision, including dura and bone), the second group (40\%) comprising grade 2 (complete excision plus apparently reliable coagulation of dural attachments) and grade 3 (complete excision of the solid tumour, though with insufficient dural coagulation or bone excision) meningiomas. Data on the proliferation index of the tumours, evaluated by Ki-67 immunohistochemical staining, were also available. The MVD was assessed by using CD105 (endoglin), which is a specific marker for neoangiogenesis in meningiomas, as already documented (22).

Immunohistochemistry. All the meningiomas were fixed in $10 \%$ neutral formalin for $24 \mathrm{~h}$ at room temperature, embedded in paraffin at $55^{\circ} \mathrm{C}$ and cut into parallel consecutive $4-\mu \mathrm{m}$ thick sections for the subsequent immunohistochemical study. Briefly, the endogenous peroxidase activity was blocked with $0.1 \% \mathrm{H}_{2} \mathrm{O}_{2}$ in methanol for 20 min then, normal sheep serum was applied for $30 \mathrm{~min}$ to prevent unspecific adherence of serum proteins. For the sstr $2 A$ epitope retrieval, specimens were submitted to microwave oven pre-treatment in $10 \mathrm{mM}$ citric acid ( $\mathrm{pH} 6.0 ; 3$ cycles for $15 \mathrm{~min}$ ), whereas the CD105 antigen was unmasked through pre-treatment with proteinase $\mathrm{K}$ (S3020, Dako Cytomation) at room temperature for $15 \mathrm{~min}$. Serial parallel sections were successively incubated at $4{ }^{\circ} \mathrm{C}$ overnight with the primary polyclonal antibody against
sstr2A (Biotrend, Germany; w.d. 1:3500) and with the primary monoclonal antibody against CD105 (Dako Corporation, Denmark, clone SN6h, w.d. 1:50). The bound primary antibodies were visualized by avidin-biotin-peroxidase detection using the Vectastain rabbit/mouse elite kit, according to the manufacturer's instructions. In order to reveal the immunostaining, the sections were incubated in darkness (24) for 10 min with 3-3' diaminobenzidine tetrahydrochloride (Sigma Chemical Co., St. Louis, MO, USA), in the amount of $100 \mathrm{mg}$ in $200 \mathrm{ml} 0.03 \%$ hydrogen peroxide in phosphatebuffered saline (PBS). Nuclear counterstaining was performed by Mayer's haemalum. Specificity of the binding was assessed by omitting the primary anti-serum or replacing it with normal rabbit serum or phosphate-buffered saline solution (PBS, $\mathrm{pH}$ 7.4). Moreover, islet cells within pancreatic human samples were used as positive controls for the sstr $2 \mathrm{~A}$ immunoreaction, whereas the syncytiotrophoblast present in specimens of human term placenta was tested as a positive control for the CD105 immunoreaction (25).

In parallel sections obtained from the same tissue blocks, the Ki-67 antigen was unmasked by retrieval procedures (10 mM, pH 6.0 sodium citrate buffer heated in a microwave oven for 3 cycles x $5 \mathrm{~min}$ ) and then Ki-67 anti-serum (clone MIB-1, Dako, Glostrup, Denmark; w.d. 1:50) was applied for $30 \mathrm{~min}$ at room temperature.

Quantification and statistics. Immunostained sections were examined at light microscopy by two independent pathologists (V.B. and G.T) who were blinded to the clinicopathological data. In the discordant cases, consensus was achieved by using a double-headed microscope. Sstr2A expression was based on the presence of membranous and/or cytoplasmic staining.

In the evaluation of sstr $2 A$ immunohistochemical reaction, immunostaining intensity (IS) was graded as 0 (negative), 1 (weak), 2 (moderate), 3 (strong); the area of staining positivity (ASP), recorded as a percentage of positive cells, was graded as follows: $0(<5 \%), 1(5-25 \%), 2(26-50 \%), 3(51-75 \%)$ and $4(76-100 \%)$, in accordance with the criteria proposed by Qiu et al (26). Then, an intensity distribution (ID) score was generated for each case by multiplying the values of IS and ASP. Cases displaying an ID score $<1$ were defined as negative. The median ID score value (ID score: 6) was used as the cut-off to discriminate between the cases with low (ID score: 1-4) and high (ID score 6-12) sstr2A expression.

On the basis of the subcellular site of the immunoreaction, positive cases were also subdivided into cases showing only a cytoplasmic staining and meningiomas displaying a cytoplasmic and membranous staining.

The quantification of microvessels was performed according to the procedure described by Weidner et al (27), already applied in our previous study on MVD in meningiomas (22). More specifically, the three most vascularized areas detected by CD105 were initially selected (so-called hot spots) under $x 40$ field. Then microvessels were counted in each of these areas under a $x 400$ field. Single endothelial cells or clusters of endothelial cells, with or without a lumen, were considered to be individual vessels. The mean value of three x400 field $\left(0.30 \mathrm{~mm}^{2}\right)$ counts was recorded as the MVD of the section. Then the MVD value was converted into the mean number of microvessels $/ \mathrm{mm}^{2}$ for the statistical analyses. The 


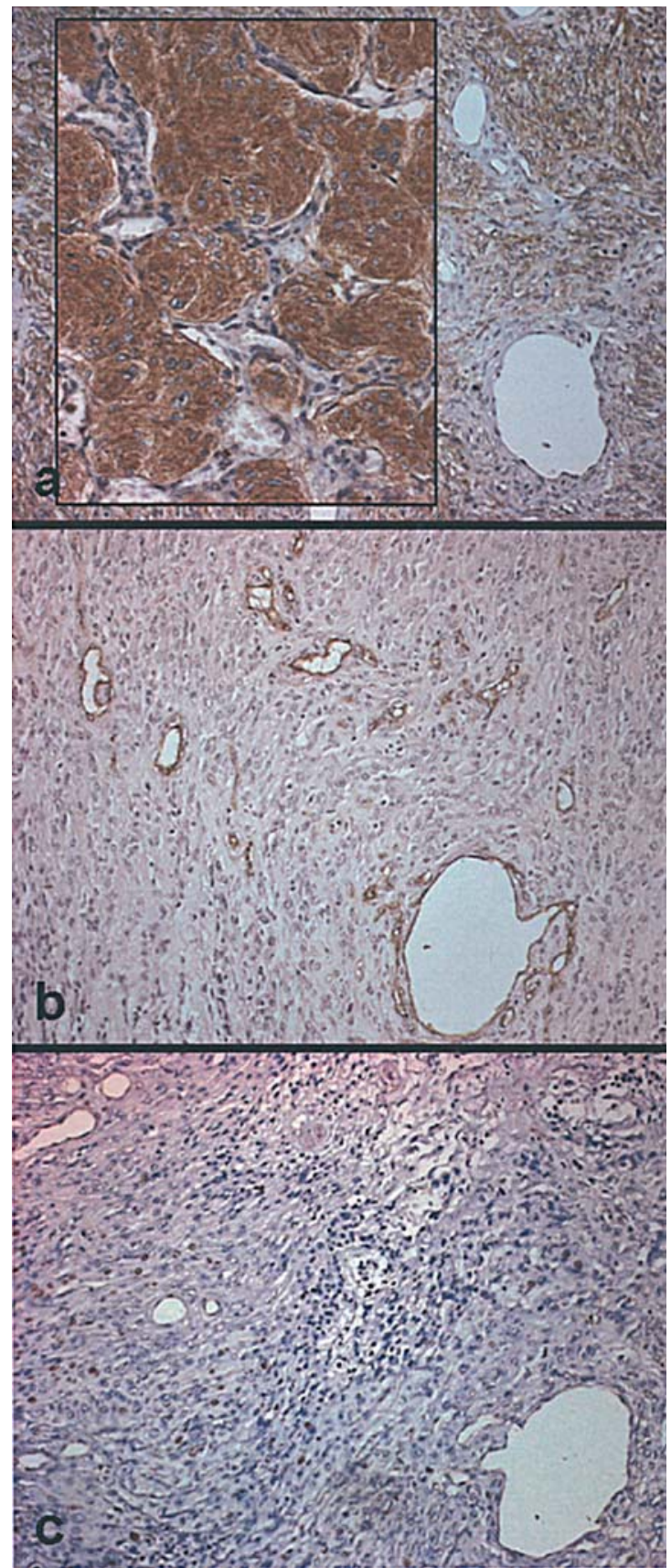

Figure 1. (a) A cytoplasmic sstr $2 A$ immunoreaction in an atypical meningioma (sstr $2 A$ staining; original magnification $\mathrm{x} 200$; insert: original magnification $\mathrm{x} 400$ ). (b) A high MVD (CD105 staining; original magnification $\mathrm{x} 200$ ) and (c) Ki-67 LI (Ki-67 staining; original magnification $\mathrm{x} 200$ ) were detected in the same case.

median MVD value (MVD: 23.33 microvessels $/ \mathrm{mm}^{2}$ ) was used as the cut-off point to discriminate between cases with a low and a high MVD.

The Ki-67 labelling index (LI) was calculated as a mean percentage by counting the stained nuclei of tumour cells for 1,000 cells in three representative neoplastic fields; each degree of nuclear staining intensity was taken into consideration. A Ki-67 value of $4 \%$ was utilized as a cut-off point to determine low and high Ki-67 expression, as suggested by Perry et al (28).

Mann-Whitney and Chi-squared tests were applied to assess the correlation between the histological grade and the

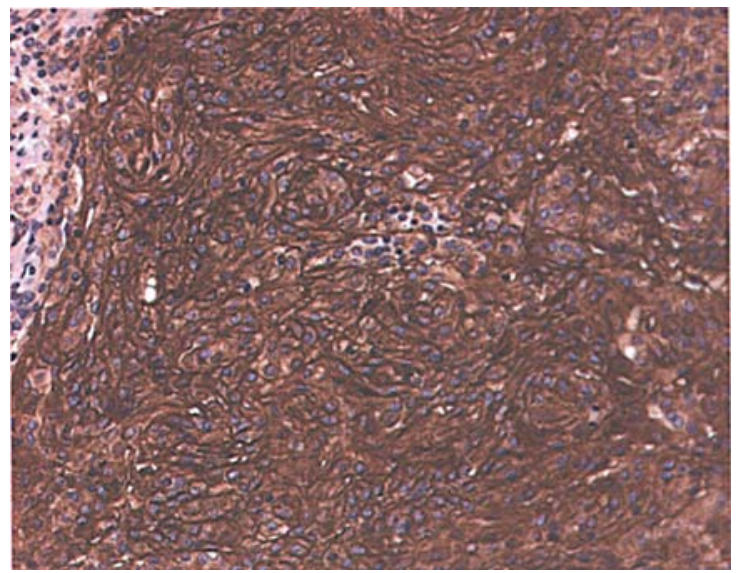

Figure 2. A strong cytoplasmic and membranous immunostaining for sstr $2 A$ in a case of atypical meningioma (sstr $2 A$ staining; original magnification $\mathrm{x} 200)$.

MVD or Ki-67 LI of the meningiomas. Grade II and III tumours were all put together in an attempt to obtain statistically comparable groups.

Fisher exact and Chi-squared tests were carried out to analyze the correlations between sstr $2 A$ expression (negative versus positive; low expression versus high expression; cytoplasmic versus membranous and cytoplasmic) and the clinicopathological variables, including the gender and age of the patients, the histological grade, site, Simpson grade and proliferative index of the meningiomas as well as the MVD of the tumours.

The Mann-Whitney test was further used to analyze the correlations between sstr $2 A$ expression and patterns of staining and the MVD of the tumours. A p-value $<0.05$ was considered statistically significant. Data were analysed using the SPSS package version 6.1.3 (SPSS Inc., Chicago, IL, USA).

\section{Results}

The clinicopathological variables, the sstr $2 \mathrm{~A}$ immunoexpression data, Ki-67 LI and the MVD counts related to the analyzed meningiomas are shown in Table I.

A sstr $2 A$ positive immunoreaction, with a variable ID score ranging between 1 and 12, was found in 26/35 (74\%) cases. In particular, sstr $2 A$ positive cases included $7 / 13$ (54\%) grade I, $16 / 19(84 \%)$ grade II and 3/3 (100\%) grade III meningiomas. Among the positive cases, a low sstr $2 A$ expression (ID score: 1-4) was recorded in $8 / 26(31 \%)$ meningiomas, whereas a high sstr $2 A$ expression (ID score: 6-12) was evidenced in $18 / 26$ $(69 \%)$ cases. Specifically, 4/7 (57\%) grade I, 12/16 grade II $(75 \%)$ and $2 / 3$ grade III $(66 \%)$ meningiomas were characterized by a high sstr $2 A$ expression. Moreover, among the sstr $2 A$ positive tumours, $12 / 26(46 \%)$ displayed a cytoplasmic staining in the neoplastic cells (Fig. 1a), whereas a cytoplasmic and membranous staining (Fig. 2) was evidenced in $14 / 26(54 \%)$ cases (Table I).

CD105 positive vessels were identified in 32/35 (91\%) meningiomas. In the positive cases, CD105 immunoreaction was observed in the endothelial cells of the stained vessels (Fig. 1b). A high MVD (MVD $\geq 23.33$ microvessels $/ \mathrm{mm}^{2}$ ), quantified through CD105 immunostaining was observed in 


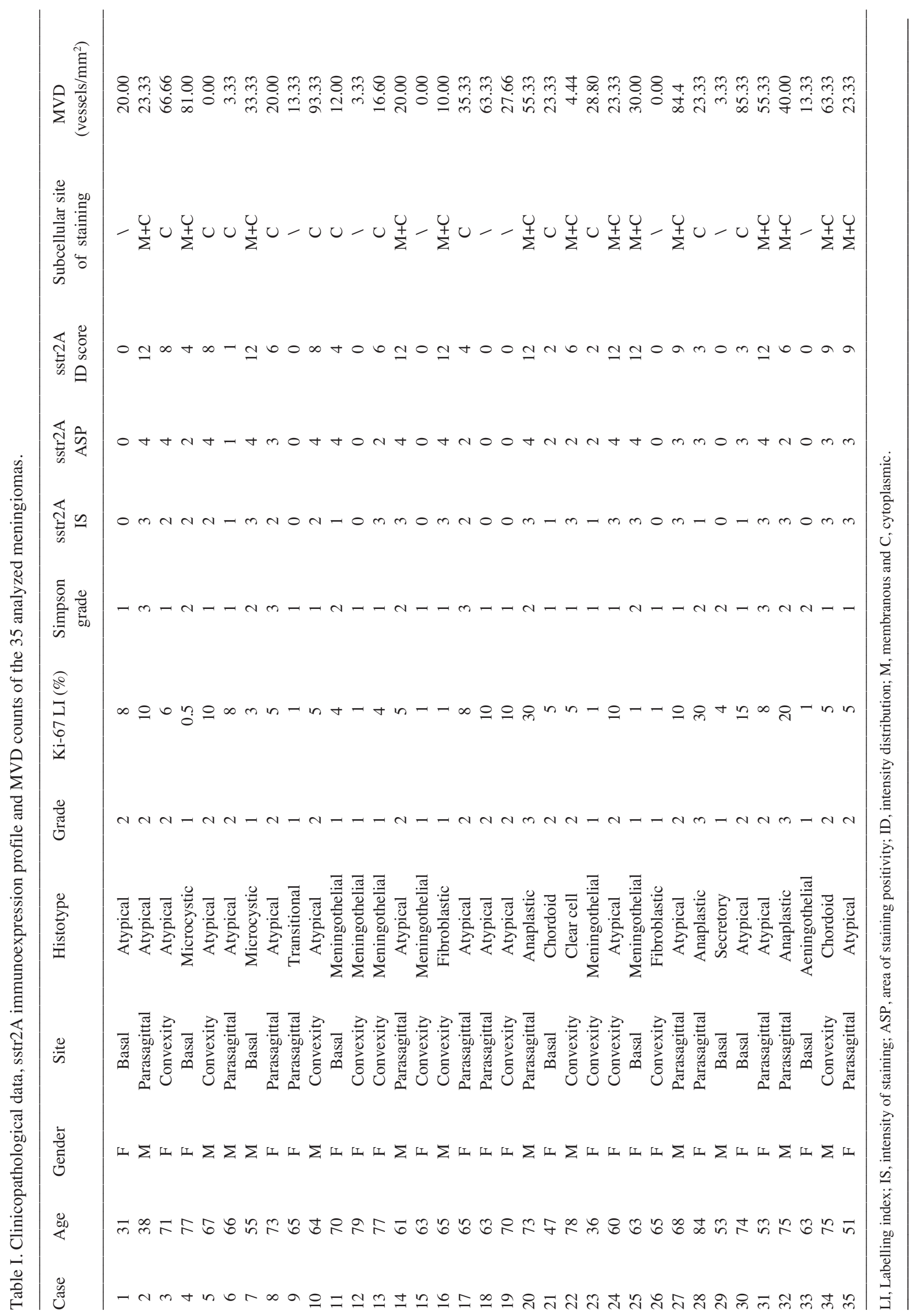


Table II. Statistical correlations between the sstr $2 A$ immunohistochemical pattern and the tumour MVD investigated through the Mann-Whitney test.

\begin{tabular}{lrcc}
\hline sstr2A & $\mathrm{n}$ & Mean rank & P-value \\
\hline Negative & 9 & 11.0556 & \\
Positive & 26 & 20.4038 & 0.0183 \\
Cytoplasmic & 12 & 12.2917 & \\
Membranous & & & \\
and cytoplasmic & 14 & 14.5357 & 0.4558 \\
Low ID score (1-4) & 8 & 13.500 & \\
High ID score (6-12) & 18 & 13.500 & 1.00 \\
\hline
\end{tabular}

Table III. Statistical correlations between sstr $2 A$ immunohistochemical expression and the clinicopathological variables of the 35 analyzed meningiomas.

\begin{tabular}{|c|c|c|c|}
\hline \multirow{2}{*}{ Variable } & \multicolumn{2}{|c|}{ sstr $2 A$} & \multirow{2}{*}{$\mathrm{P}$} \\
\hline & Negative & Positive & \\
\hline \multicolumn{4}{|l|}{ Age } \\
\hline$<65$ yrs & 5 & 10 & \\
\hline$\geq 65$ yrs & 4 & 16 & 0.451 \\
\hline \multicolumn{4}{|l|}{ Gender } \\
\hline Male & 1 & 12 & \\
\hline Female & 8 & 14 & 0.109 \\
\hline \multicolumn{4}{|l|}{ Site } \\
\hline Convexity & 4 & 9 & \\
\hline Parasagittal & 2 & 11 & \\
\hline Basal & 3 & 6 & 0.556 \\
\hline \multicolumn{4}{|l|}{ Grade } \\
\hline I & 6 & 7 & \\
\hline II & 3 & 19 & 0.05 \\
\hline \multicolumn{4}{|l|}{ Ki-67 LI } \\
\hline$\leq 4 \%$ & 6 & 7 & \\
\hline$>4 \%$ & 3 & 19 & 0.05 \\
\hline \multicolumn{4}{|l|}{ Simpson } \\
\hline 1 & 7 & 14 & \\
\hline $2-3$ & 2 & 12 & 0.262 \\
\hline \multicolumn{4}{|l|}{ MVD } \\
\hline Low $\left(<23.33\right.$ vessels $\left./ \mathrm{mm}^{2}\right)$ & 7 & 8 & \\
\hline $\operatorname{High}\left(\geq 23.33\right.$ vessels $\left./ \mathrm{mm}^{2}\right)$ & 2 & 18 & 0.022 \\
\hline
\end{tabular}

16 high grade (grade II- and III), in 2 microcystic and in 1 meningothelial meningiomas (Table I).

Variously represented Ki-67 nuclear reactivity was found in meningiomas (Fig. 1c), with a rate of stained cells ranging from 0.5 to $30 \%$ (mean value $7 \%$ ). All grade II and III meningiomas displayed a Ki-67 LI >4\% (Table I).

A significant correlation was found between a high MVD and a high histological grade (II-III) $(\mathrm{P}=0.0185)$ or Ki-67 LI $(\mathrm{Ki}-67>4 \%)(\mathrm{P}=0.0039)$.
Table IV. Statistical correlations between the sstr $2 A$ ID score and the clinicopathological variables in the 26 sstr $2 A$ positive meningiomas.

\begin{tabular}{|c|c|}
\hline \multirow{2}{*}{ Variable } & sstr $2 A$ ID score \\
\hline & $6-12$ \\
\hline
\end{tabular}

Age

$<65$ yrs

$\geq 65$ yrs

28

Gender

Male

Female

$6 \quad 10$

0.420

Site

Convexity

Parasagittal

Basal

$2 \quad 11$

$\begin{array}{ll}6 & 7\end{array}$

0.202

Grade

I

II-III

Ki-67 LI

$\leq 4 \%$

$>4 \%$

$\begin{array}{ll}1 & 8 \\ 3 & 8 \\ 4 & 2\end{array}$

0.070

Simpson

1

$2-3$

$\begin{array}{rr}3 & 4 \\ 5 & 14\end{array}$

0.635

MVD

Low $\left(<23.33\right.$ vessels $\left./ \mathrm{mm}^{2}\right) \quad 2 \quad 8$

High $\left(\geq 23.33\right.$ vessels $\left./ \mathrm{mm}^{2}\right) \quad 6 \quad 12 \quad 0.669$

When meningiomas were subdivided on the basis of sstr $2 A$ expression, sstr $2 A$ positive cases were found to display a significantly higher MVD than sstr $2 A$ negative cases $(\mathrm{P}=0.0183)$ (Table II). The statistically significant association between sstr $2 A$ positive immunoreaction and a high MVD ( $\geq 23.33$ microvessels $/ \mathrm{mm}^{2}$ ) was confirmed through the Fisher exact test $(\mathrm{P}=0.022)$ (Table III). Even if statistical significance was not reached, an association was evidenced between sstr $2 A$ expression and a high histological grade or Ki-67 LI ( $\mathrm{P}=0.05)$ (Table III). When sstr $2 A$ expression was correlated with the histological grade and Ki-67 LI of the meningiomas of our series excluding the microcystic ones, which emerged as grade I highly vascularized tumours both of which expressed sstr2A (Fig. 3), a significant correlation was evidenced between a positive sstr $2 \mathrm{~A}$ immunohistochemical reaction and a higher histological grade (II-III) and growth fraction (Ki-67 LI> 4\%) $(\mathrm{P}=0.033)$.

When only the sstr $2 A$ positive cases were taken into consideration, no significant correlation emerged between the subcellular site of staining (cytoplasmic versus cytoplasmic and membranous) or the rate of $s s t r 2 A$ immunoexpression (low ID score versus ID score) and the clinicopathological parameters as well as the MVD of the tumours (Table IV and V). 
Table V. Statistical correlations between the subcellular site of sstr $2 A$ immunohistochemical staining and the clinicopathological variables in the 26 sstr $2 A$ positive meningiomas.

\begin{tabular}{|c|c|c|c|}
\hline \multirow{2}{*}{ Variable } & \multicolumn{2}{|c|}{ sstr $2 A$ staining } & \multirow{2}{*}{ P-value } \\
\hline & Cytoplasmic & Membranous and cytoplasmic & \\
\hline \multicolumn{4}{|l|}{ Age } \\
\hline$<65 \mathrm{yrs}$ & 3 & 7 & \\
\hline$\geq 65 \mathrm{yrs}$ & 9 & 7 & 0.248 \\
\hline \multicolumn{4}{|l|}{ Gender } \\
\hline Male & 3 & 9 & \\
\hline Female & 9 & 5 & 0.062 \\
\hline \multicolumn{4}{|l|}{ Site } \\
\hline Convexity & 5 & 4 & \\
\hline Parasagittal & 4 & 7 & \\
\hline Basal & 3 & 3 & 0.780 \\
\hline \multicolumn{4}{|l|}{ Grade } \\
\hline I & 3 & 4 & \\
\hline II-III & 10 & 9 & 1.00 \\
\hline \multicolumn{4}{|l|}{ Ki-67 LI } \\
\hline$\leq 4 \%$ & 3 & 4 & \\
\hline$>4 \%$ & 9 & 10 & 1.00 \\
\hline \multicolumn{4}{|l|}{ Simpson } \\
\hline 1 & 8 & 6 & \\
\hline $2-3$ & 4 & 8 & 0.267 \\
\hline \multicolumn{4}{|l|}{ MVD } \\
\hline Low $\left(<23.33\right.$ vessels $\left./ \mathrm{mm}^{2}\right)$ & 5 & 7 & \\
\hline $\operatorname{High}\left(\geq 23.33\right.$ vessels $\left./ \mathrm{mm}^{2}\right)$ & 3 & 10 & 0.411 \\
\hline
\end{tabular}

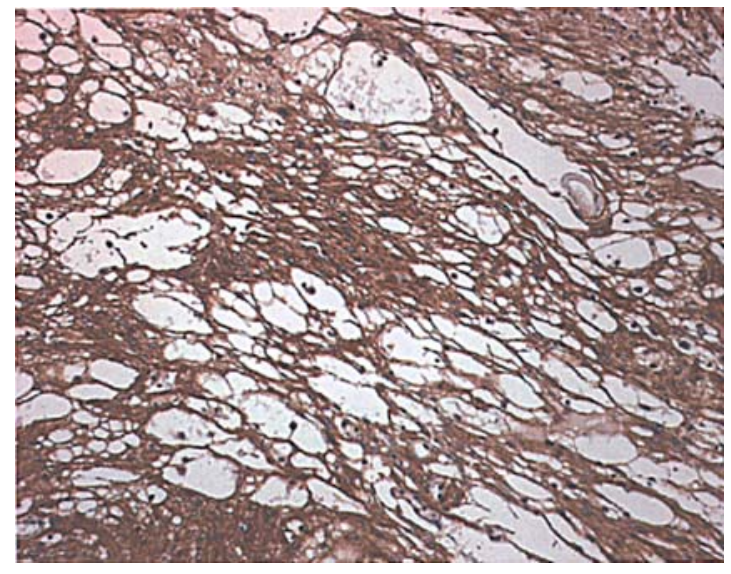

Figure 3. A microcystic meningioma showing a strong immunohistochemical reaction to $s$ str $2 A$ with a cytoplasmic and membranous subcellular localization (sstr2A staining; original magnification $\mathrm{x} 100)$.

\section{Discussion}

In human meningiomas, the expression of sstrs has been largely explored through different techniques such as in vitro autoradiography, immunohistochemistry and RT-PCR (14,16-18,29).

The majority of these tumours have been found to express a high density of sstrs compared to the surrounding tissue, which allows them to be readily visualized by in vivo receptor imaging methods using labelled somatostatin analogues such as octreotide (30). The demonstration of sstr expression in meningiomas provides a molecular basis for utilizing novel therapeutic strategies with somatostatin analogues in the treatment of these neoplasias (18). It has been shown that somatostatin exerts an anti-proliferative effect in vitro on meningiomas displaying sstr expression (18). Somatostatin anti-tumoural activity is not only due to its anti-proliferative action, but also to its ability to inhibit the neo-angiogenic process by reducing the tumour cell-derived VEGF secretion $(3,4,31)$. In human meningiomas, the proliferation index and the MVD, which reflects the intratumoural neo-angiogenesis, appear to increase together with the histological grade (20-22). Thus meningiomas displaying a higher histological grade may represent a suitable candidate to therapies with somatostatin analogues. Nonetheless, the expression of sstrs, which represent the essential condition for such therapies to have an effect, has been barely evaluated in grade II and III meningiomas up to now $(14,16-18)$. In view of this, in the present study we analyzed the expression of sstr $2 A$, which mediates the anti-proliferative and anti-angiogenic effects of somatostatin, in a series of grade II and III meningiomas and compared it with the data obtained in grade I cases in an attempt to evaluate whether the sstr $2 A$ expression is linked to a higher biological aggressiveness of meningiomas. Furthermore, we correlated the presence of sstr $2 \mathrm{~A}$ immuno- 
labelling and its pattern with the proliferation index and the MVD of meningiomas in order to verify whether sstr $2 A$ positive tumours are characterized by a high growth fraction and neo-angiogenesis, which represent the targets for somatostatin analogue therapy.

We found a high sstr $2 A$ immunohistochemical expression in the majority of the analyzed meningiomas and demonstrated that grade II and III tumours frequently express this receptor in their neoplastic cells (84 and 100\% of cases, respectively). Moreover, in our series, the cases expressing sstr $2 A$ were found to exhibit a significantly higher MVD than the sstr2A negative meningiomas, thus suggesting that somatostatin analogues may be relevant in the treatment of meningiomas by reducing their blood supply. MVD was assessed by using an antibody against the specific marker for neo-angiogenesis CD105, which is a $180 \mathrm{kDa}$ transmembrane glycoprotein (32), specifically expressed by cycling endothelial cells of newly formed vessels in inflamed or in regenerating tissues, or in tumours $(32,33)$, all of which undergo active angiogenesis. By contrast, it is only weakly expressed or absent in the vessels of normal tissues (34). Thus it represents a powerful marker of neovascularization in human meningiomas, as well as in other types of tumours, in comparison to pan-endothelial markers, such as CD31 and CD34 (22,35-37).

Although we demonstrated the existence of a significant correlation between the MVD and the histological grade and Ki-67 LI of the analyzed meningiomas, no significant correlation between the latter two parameters and the sstr $2 \mathrm{~A}$ expression emerged in our study. Nonetheless, our series comprised two microcystic meningiomas, which, in spite of their histological grade I, are highly vascularized tumours $(22,38)$. When the correlation between sstr $2 A$ expression and the histological grade and growth fraction of the meningiomas was investigated by excluding these cases, sstr $2 \mathrm{~A}$ expression appeared to be significantly associated with a high histological grade and Ki-67 LI of the tumours. Thus, sstr $2 \mathrm{~A}$ expression seems to parallel the existence of an extensive neo-angiogenic process rather than the malignant progression of meningiomas. As a consequence, somatostatin analogue therapies may be effective on highly vascularized meningiomas in spite of their histological grade.

A recent study has reported that only the membranous, rather than cytoplasmic, sstr $2 \mathrm{~A}$ immunostaining is correlated with the clinical response to somatostatin analogues in patients affected by neuroendocrine tumours (39). In previous studies describing sstr $2 A$ immunohistochemical expression in human meningiomas, the subcellular distribution of the immunoreaction was not clearly specified and discussed $(14,16,17)$. In the present study, we stratified for the first time the sstr $2 \mathrm{~A}$ positive meningiomas according to their subcellular pattern of staining, in order to verify the frequency of membranous sstr $2 A$ staining and its eventual correlation with other parameters. In our series, a cytoplasmic staining co-existed in all cases which were characterized by a membranous one. None of the subcellular patterns of immunolabelling was prevalent in the sstr $2 A$ positive meningiomas. Moreover, we did not find any significant association between the subcellular localization of the immunoreaction and the clinicopathological characteristics, such as the histological grade and the growth fraction of the tumours, or their MVD. The observation of a cytoplasmic localization of $s s t r 2 A$ in almost half of the positive meningiomas raises the question whether these receptors remain accessible in vivo to somatostatin analogues and permit therapeutic applications. A recent pilot study described the progression-free survival at six months as a result of treatment with long-acting somatostatin in a subset of patients with recurrent meningiomas shown to overexpress sstrs by octreotide scintigraphy (40). However, the evaluation of sstrs by this technique does not allow the sstr subtype to be defined, in contrast to the immunohistochemical procedure. Thus, further investigations correlating the sstr $2 \mathrm{~A}$ immunohistochemical pattern and the sstr scintigraphy as well as the response to the therapy with somatostatin analogues are needed. Specifically, it would be worth examining whether such a therapy is effective only on meningiomas displaying a membranous sstr $2 A$ staining or also on those with a merely cytoplasmic immunoreaction.

In conclusion, the present study demonstrates the existence of a correlation between sstr $2 A$ expression and the entity of neo-angiogenesis in meningiomas, thus providing the basis for the use of somatostatin analogue-based therapies, which have an anti-angiogenic effect, in the treatment of these tumours. On the basis of our findings, the meningiomas characterized by a higher MVD, such as atypical, anaplastic and microcystic ones, appear as the most suitable candidates for such therapies, which may be used on recurring or partially resected tumours. We suggest to preliminarily test the tumour samples for sstr2A immunohistochemical reaction; indeed this receptor subtype is the one mediating the anti-proliferative and antiangiogenic effects of somatostatin.

\section{References}

1. Epelbaum J, Dournaud P, Fodor M and Viollet C: The neurobiology of somatostatin. Crit Rev Neurobiol 8: 25-44, 1994.

2. Epelbaum J: Somatostatin in the central nervous system: physiology and pathological modifications. Prog Neurobiol 27: 63-100, 1986

3. Reubi JC and Laissue JA: Multiple action of somatostatin in neoplastic disease. Trends Pharmacol Sci 16: 110-115, 1995.

4. Ribatti D, Conconi MT and Nussdorfer GG: Nonclassic endogenous novel regulators of angiogenesis. Pharmacol Rev 59: 185-205, 2007.

5. Florio T: Molecular mechanisms of the antiproliferative activity of somatostatin receptors (SSTRs) in neuroendocrine tumors. Front Biosci 13: 822-840, 2008.

6. Patel YC: Somatostatin and its receptor family. Front Neuroendocrinol 20: 157-198, 1999.

7. Patel YC, Greenwood MT, Panetta R, Demchyshyn L, Niznik H and Srikant CB: Multiple gene transcription of the somatostatin receptor SSTR2: tissue selective distribution and CAMP regulation. Biochem Biophys Res Commun 192: 288-294, 1993.

8. Reubi JC, Laissue JA, Waser B, Steffen DL, Hipkin RW and Schonbrunn A: Immunohistochemical detection of sst $2 \mathrm{~A}$ receptor in lymphatic, smooth muscular, and peripheral nervous system of human gastrointestinal tract: facts and artefacts. J Clin Endocrinol Metab 84: 2942-2950, 1999.

9. Breder CD, Yamada Y, Yasuda K, Seino S, Saper CB and Bell GI: Differential expression of somatostatin receptor subtypes in brain. J Neurosci 12: 3920-3934, 1992.

10. Goodyer CG, Grigorakis SI, Patel YC and Kumar U: Developmental changes in the expression of somatostatin receptors (1-5) in the brain, hypothalamus, pituitary and spinal cord of the human fetus. Neuroscience 125: 441-448, 2004.

11. Lamberts SW, Krenning EP and Reubi JC: The role of somatostatin and its analogous in the diagnosis and treatment of tumours. Endocr Rev 12: 450-482, 1991.

12. Reubi JC, Waser B, Schaer JC and Markwalder R: Somatostatin receptors in human prostate and prostate cancer. J Clin Endocrinol Metab 80: 2806-2814, 1995. 
13. Schaer JC, Waser B, Mengod G and Reubi JC: Somatostatin receptor subtypes sst1, sst2, sst3 and sst5 expression in human pituitary, gastroentero-pancreatic and mammary tumors: comparison of mRNA analysis with receptor autoradiography. Int J Cancer 70: 530-537, 1997.

14. Dutour A, Kumar U, Panetta R, Ouafik L, Fina F, Sasi R and Patel YC: Expression of somatostatin receptor subtypes in human brain tumours. Int J Cancer 76: 620-627, 1998.

15. Reubi JC, Waser B, Liu Q, Laissue JA and Schonbrunn A: Subcellular distribution of somatostatin sst2A receptors in human tumours of the nervous and neuroendocrine systems: membranous versus intracellular location. J Clin Endocrinol Metab 85: 3882-3890, 2000.

16. Reubi JC, Kappeler A, Waser B, Laissue J, Hipkin RW and Schonbrunn A: Immunohistochemical localization of somatostatin receptors sst2A in human tumours. Am J Pathol 153: 233-245, 1998.

17. Schulz S, Pauli SU, Schulz S, Händel M, Dietzmann K, Firsching R and Höllt V: Immunohistochemical determination of five somatostatin receptors in meningiomas reveals frequent overexpression of somatostatin receptor subtype sst2A. Clin Cancer Res 6: 1865-1874, 2000.

18. Arena S, Barbieri F, Thellung S, et al: Expression of somatostatin receptor mRNA in human meningiomas and their implication in in vitro antiproliferative activity. J Neurooncol 66: 155-166, 2004.

19. Louis DN, Ohgaki H, Wiestler OD, Cavenee WK (eds): WHO Classification of Tumours of the Central Nervous System. IARC Press, Lyon, 2007.

20. Kayaselçuk F, Zorludemir S, Bal N, Erdogan B, Erdogan S and Erman T: The expression of survivin and Ki-67 in meningiomas: correlation with grade and clinical outcome. J Neurooncol 67: 209-214, 2004.

21. Pistolesi S, Boldrini L, Gisfredi S, et al: Angiogenesis in intracranial meningiomas: immunohistochemical and molecular study. Neuropathol Appl Neurobiol 30: 118-125, 2004.

22. Barresi V, Cerasoli S, Vitarelli E and Tuccari G: Density of microvessels positive for CD105 (endoglin) is related to prognosis in meningiomas. Acta Neuropathol 114: 147-156, 2007.

23. Simpson D: The recurrence of intracranial meningiomas after surgical treatment. J Neurol Neurosurg Psychiatry 20: 22-39, 1957.

24. Weir EE, Pretlow TG and Pitts A: A more sensitive and specific histochemical peroxidase stain for the localization of cellular antigen by the enzyme-antibody conjugated method. J Histochem Cytochem 22: 1135-1140, 1974

25. Gougos A, St Jacques S, Greaves A, et al: Identification of distinct epitopes of endoglin, an RGD-containing glycoprotein of endothelial cells, leukemic cells, and syncytiotrophoblasts. Int Immunol 4: 83-92, 1992.

26. Qiu CZ, Wang C, Huang ZX, Zhu SZ, Wu YY and Qiu JL: Relationship between somatostatin receptor subtype expression and clinicopathology, Ki-67, Bcl-2 and p53 in colorectal cancer. World J Gastroenterol 12: 2011-2015, 2006.

27. Weidner N, Semple JP, Welch WR and Folkman J: Tumor angiogenesis and metastasis-correlation in invasive breast carcinoma. N Engl J Med 324: 1-8, 1991.
28. Perry A, Stafford SL, Scheithauer BW, Suman VJ and Lohse CM The prognostic significance of MIB-1, p53, and DNA flow cytometry in completely resected primary meningiomas. Cancer 82: 2262-2269, 1998

29. Reubi JC, Maurer R, Klijn JG, et al: High incidence of somatostatin receptors in human meningiomas: biochemical characterization. J Clin Endocrinol Metab 63: 433-438, 1986.

30. Hildebrandt G, Scheidhauer K, Luyken C, Schicha H, Klug N, Dahms P and Krisch B: High sensitivity of the in vivo detection of somatostatin receptors by 111 indium (DTPA-octreotide)scintigraphy in meningioma patients. Acta Neurochir 126: 63-71, 1994

31. Lawnicka H, Stepien H, Wyczólkowska J, Kolago B, Kunert-Radek J and Komorowski J: Effect of somatostatin and octreotide on proliferation and vascular endothelial growth factor secretion from murine endothelial cell line (HECa10) culture. Biochem Biophys Res Commun 268: 567-571, 2000.

32. Cheifetz S, Bellon T, Cales C, et al: Endoglin is a component of the transforming growth factor-beta receptor system in human endothelial cells. J Biol Chem 267: 19027-19030, 1992.

33. Burrows FJ, Derbyshire EJ, Tazzari PL, et al: Up-regulation of endoglin on vascular endothelial cells in human solid tumours: implications for diagnosis and therapy. Clin Cancer Res 1: 1623-1634, 1995.

34. Wang JM, Kumar S, Pye D, van Aghtoven AJ, Krupinski J and Hunter RD: A monoclonal antibody detects heterogeneity in vascular endothelium of tumours and normal tissues. Int $\mathrm{J}$ Cancer 54: 363-370, 1993.

35. Fonsatti E, Altomonte M, Arslan P and Maio M: Emerging role of endoglin (CD105) as a marker of angiogenesis with clinical potential in human malignancies. Curr Cancer Drug Targets 3: 427-432, 2003

36. Dallago CM, Oliveira MC, Barbosa-Coutinho LM and Ferreira NP: Angiogenesis in craniopharyngiomas: Microvascular density and tissue expression of the vascular endothelial growth factor (VEGF) and endostatin. Endocr Pathol 16: 355-362, 2005.

37. Yao Y, Kubota T, Takeuchi $\mathrm{H}$ and Sato K: Prognostic significance of microvessel density determined by an antiCD105/endoglin monoclonal antibody in astrocytic tumors: comparison with an anti-CD31 monoclonal antibody. Neuropathology 25: 201-206, 2005.

38. Christov C, Lechapt-Zalcman E, Adle-Biassette H, Nachev S and Gherardi RK: Vascular permeability factor/vascular endothelial growth factor (VPF/VEGF) and its receptor flt-1 in microcystic meningiomas. Acta Neuropathol 98: 414-420, 1999.

39. Volante M, Brizzi MP, Faggiano A, et al: Somatostatin receptor type $2^{\circ}$ immunohistochemistry in neuroendocrine tumours: a proposal of a scorino system correlated with somatostatin receptor scintigraphy. Modern Pathol 20: 1172-1182, 2007.

40. Chamberlain MC, Glantz MJ and Fadul CE: Recurrent meningioma: salvage therapy with long-acting somatostatin analogue. Neurology 69: 969-973, 2007. 